\title{
Concordance between indirect fibrosis and steatosis indices and their predictors in subjects with overweight/obesity
}

\section{Melania Gaggini}

Istituto di Fisiologia Clinica Consiglio Nazionale delle Ricerche

\section{Luisella Vigna}

Ospedale Maggiore di Milano Policlinico: Fondazione IRCCS Ca' Granda Ospedale Maggiore Policlinico

\section{Salvina Di Piazza}

Ospedale Maggiore di Milano Policlinico: Fondazione IRCCS Ca' Granda Ospedale Maggiore Policlinico

Francesca Gori

Ospedale Maggiore di Milano Policlinico: Fondazione IRCCS Ca' Granda Ospedale Maggiore Policlinico Amedea Silvia Tirelli

Ospedale Maggiore di Milano Policlinico: Fondazione IRCCS Ca' Granda Ospedale Maggiore Policlinico

\section{Fabrizia Bamonti}

Universita degli Studi di Milano

\section{Maristella Maltinti}

CNR di Pisa: Consiglio Nazionale delle Ricerche Area della Ricerca di Pisa

\section{Filomena Napolitano}

Ospedale Maggiore di Milano Policlinico: Fondazione IRCCS Ca' Granda Ospedale Maggiore Policlinico

\section{Kiriazoula Chatzianagnostou}

CNR di Pisa: Consiglio Nazionale delle Ricerche Area della Ricerca di Pisa

Cristina Vassalle ( $\nabla$ cristina.vassalle@ftgm.it)

Fondazione CNR-REgione Toscana G Monasterio https://orcid.org/0000-0003-3438-6450

\section{Research Article}

Keywords: non-invasive indices, fibrosis, steatosis, concordance, overweight and obesity

Posted Date: February 8th, 2022

DOI: https://doi.org/10.21203/rs.3.rs-1326627/v1

License: (1) (1) This work is licensed under a Creative Commons Attribution 4.0 International License.

Read Full License 
Concordance between indirect fibrosis and steatosis indices and their predictors in subjects with overweight/obesity

'Gaggini M, ${ }^{3}$ Vigna L, ${ }^{3}$ Di Piazza S, ‘Gori F, sTirelli AS, 'Bamonti F, ${ }^{2}$ Maltinti M, ${ }^{5}$ Napolitano $\mathrm{F}$, ${ }^{2}$ Chatzianagnostou $\mathrm{K},{ }^{*}$ Vassalle $\mathrm{C}$

Institute of Clinical Physiology, CNR, Pisa, Italy; 'Fondazione CNR-Toscana Gabriele

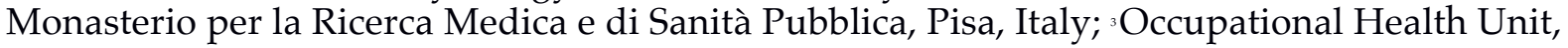
Center of Obesity and Work EASO Collaborating Centers for Obesity Management, Fondazione $\mathrm{Ca}^{\prime}$ Granda Ospedale Maggiore Policlinico, Milan, Italy; 'Department of Anesthesia, Critical Care and Emergency, Fondazione IRCCS Ca' Granda - Ospedale Maggiore Policlinico, Milan, Italy; 'Laboratory of Clinical Chemistry and Microbiology Fondazione IRCCS $\mathrm{Ca}^{\prime}$ Granda, Ospedale Maggiore Policlinico, Milan, Italy; 'Former Associate Professor of Clinical Biochemistry, Specialized in Clinical Chemistry and Biochemistry, Università degli Studi di Milano, Milan, Italy.

${ }^{*}$ Correspondence to: Cristina Vassalle, Fondazione Toscana Gabriele Monasterio per la Ricerca Medica e di Sanità Pubblica Pisa, Italy, CNR via Moruzzi 156100 Pisa Italy tel +390503253525 email:cristina.vassalle@ftgm.it 


\begin{abstract}
Background: The non-invasive assessment of steatosis/fibrosis tried to overcome some of periprocedural risk of liver biopsy; for this several indices of steatosis and fibrosis in liver have been proposed. Aim: to evaluate concordance of non invasive fibrosis and steatosis indices in a large population of adult subjects at risk of NAFLD, and their relationship with different clinical and biochemical parameters.

Methods: Indices of steatosis (fatty liver index-FLI), NAFLD liver fat score-NLFS)) and fibrosis (Fibrosis 4 (FIB-4), BARD, BAAT and FORN) were calculated in 1145 outpatients with overweight or obesity at risk for T2D and NAFLD. Indices were correlated with clinical variables.

Results: Concordance between tests occurred in $81 \%$ of the overall values between FLI and NLFS, but was lower when comparing the other fibrosis scores (FIB-4 vs FORN 72\%, FIB-4 vs BARD $36 \%$, BARD vs FORN 46\%, BARD vs BAAT 58\%, FIB-4 vs BAAT 46\%, BAAT vs FORN 62\%). Each index was differently correlated with anthropometric, clinical and laboratory variables. Conclusion: Indices evaluated retain low concordance, clinicians should be aware of these differences between steatosis/fibrosis scores when expressing a differential liver disease diagnosis or assessing the progression of a known liver disease.
\end{abstract}

Level of Evidence

Level V, descriptive research.

Key words: non-invasive indices; fibrosis; steatosis; concordance; overweight and obesity.

\title{
1.Introduction
}

Obesity diffusion have reached epidemic proportions in developed countries, in parallel to its comorbidities, which mainly include type 2 diabetes (T2D), and insulin resistance (IR). Obesity as well as IR are recognized determinants of nonalcoholic fatty liver disease (NAFLD), which progression can lead to hepatic fibrosis and cirrhosis and a new definition, ie Metabolic (dysfunction) -Associated Fatty Liver Disease (MAFLD), has been recently proposed 2 . The current estimated prevalence of NAFLD in the general population is $25 \%$ and increases $55 \%$ in patients with $\mathrm{T}_{2} \mathrm{D}^{3}$ and it is estimated that NASH prevalence will increase by $15-56 \%$, while liver mortality and advanced liver disease will more than double as a result of an aging/increasing population making early detection peremptorys.

Liver biopsy is considered as the gold standard for assessing NAFLD because it provides a direct visualization of fibrosis. However, the large prevalence of the disease and the invasiveness of liver biopsy prone to use non-invasive scores, based either on imaging, clinical and/or laboratory variables ${ }^{s}$

Non invasive biomarkers of liver fibrosis/steatosis have been widely used in studies involving the general population or primary care ${ }^{9}$. These non-invasive blood and parametric indices can be easily implemented, retaining possibility of monitoring, as well as low cost and high patient compliance.

Aim of the study was to evaluate concordance of recently proposed noninvasive alternative fibrosis and steatosis indices in a large population of adult subjects with overweight/obesity. Moreover, if it is recognized that the progression of NAFLD itself mainly depends on the presence of obesity, IR and T2D, it is also evident that not all subjects with obesity, and/or those with metabolic syndrome (MS) develop steatosis, as well as not all subjects with hepatic steatosis progress towards fibrosis or cirrhosis. Thus, as the definition of risk factors remains probably the most unresolved point in prognostic terms, we also aimed to assess clinical and biochemical significant determinants of these indices in 
this specific population.

\section{Subjects and Methods}

A total of 1145 outpatients with overweight or obesity at risk for T2D (mean age $54 \pm 14$ years; 856 females), were recruited at two hospitals (Obesity and Work Center, Clinica del Lavoro "L. Devoto" of Fondazione Ca' Granda Ospedale Maggiore, Policlinico of Milan, and Fondazione CNR-Regione Toscana G. Monasterio, Pisa, Italy) ". Patients were sent by general practitioners or occupational medicine doctors for cardiometabolic prevention and overweight/obesity treatment. The study was approved by the Ethics Committee of Milan Policlinico Hospital (Study registration number: 1370).

Upon entering the study, each participant signed an informed consent form and underwent medical examination. The study was approved by the Ethics Committee of Milan Policlinico Hospital (Study registration number: 1370). Because of the importance of reducing bias associated with obesity, we used people-first language according to the standard recommendation of The Obesity Society, Canadian Obesity Network, Italian Dietetic Association (ADI), European Association for Study of Obesity (EASO) ${ }^{12,13}$.

Arterial hypertension was defined as follow: when systolic blood pressure $>140 \mathrm{mmHg}$ and / or diastolic pressure $>90 \mathrm{mmHg}$ or use of antihypertensive medication. Dyslipidemia was considered when total cholesterol was $\geq 200 \mathrm{mg} / \mathrm{dL}$, or triglyceride $\geq 150 \mathrm{mg} / \mathrm{dL}$, or patient currently use lipid-lowering drugs.

Exclusion criteria were the following: (1) presence of systemic diseases (e.g. inflammatory diseases, cancer) (2) viral or alchool-related diseases (3) patients refusing or unable to supply written Informed Consent.

During medical examination, eligibility was evaluated by standard routine examination including body mass index (BMI), waist circumference, systolic and diastolic blood pressure. Peripheral blood samples were drawn after an overnight fast. Plasma glycated haemoglobin was measured by High-Performance Liquid Chromatography (HPLC). Complete blood count was determined on whole blood with Sysmex instrument (Dasit), and routine biochemical parameters (serum uric acid, glucose, insulin, a complete lipid profile) were measured by standard automatized laboratory analysers. Serum samples of all the subjects were frozen and stored at $-80^{\circ} \mathrm{C}$ for batch analysis periodically assessed at Central Laboratory of Policlinico of Milan or FTGM Laboratory, Pisa.

Data availability on request from the authors. The data that support the findings of this study are available from the corresponding author, [CV], upon reasonable request. We used several non invasive score for steatosis: FLI " ${ }^{1}$, and fibrosis NLFS ${ }^{15}$, Fib4 ${ }^{\circ}$, BARD ", FORN sand BAAT ${ }^{19}$. Calculation and cut-off of non-invasive scores of steatosis and fibrosis were reported in Table 1

\section{STATISTICAL ANALYSIS}

Continuous variables were reported as mean \pm SD, or as median and interquartile range for not normally distributed parameters. Categorical data are presented as number (\%). Parameters with elevated skewness were analysed with Mann Whitney (non-parametric test). Comparisons between continuous variables were evaluated by the Student's t-test, while differences between categorical variables made by $\chi 2$ analysis. A p value 0.05 was considered statistically significant.

\section{RESULTS}


Anthropometric parameters, clinical characteristics and laboratory markers in the overall population are reported in Table 2 . There were $740(65 \%)$ subjects with obesity, the overall prevalence of metabolic syndrome was $44 \%$.

Following cut-off were considered for each score: steatosis absence with values $<30$ for FLI, $\leq-0.64$ for NLFS; fibrosis absence with values $\leq 4.2$ for FORN, $\leq 3.25$ for FIB- $4,<2$ for BAAT and BARD. In the overall population, according to the FLI score, 234 tests $(20 \%)$ resulted positive for steatosis whereas only $56(5 \%)$ positive according to NLFS criteria (Figure 1). Instead, as regards fibrosis score, $495(40 \%), 173(15 \%), 881(77 \%)$ and $731(34 \%)$ were positive for FORN, FIB-4, BARD and BAAT, respectively (Figure 1).

Concordance between steatosis tests occurred in $81 \%$ of the overall values between FLI and NLFS, but lower when comparing the other fibrosis scores (FIB-4 vs FORN 72\%, FIB-4 vs BARD 36\%, BARD vs FORN 46\%, BARD vs BAAT 58\%, FIB-4 vs BAAT 46\%, BAAT vs FORN 62\%) (Table 3).

Tables 3 \& 4 report the anthropometric, clinical and laboratory parameters according to different positivity criteria for each score. As liver damage was considered in all index, liver enzymes (GGT, ALT and AST) were not reported in the table. Moreover, the parameters included in the formula for calculation of a specific index are excluded . For steatosis, FLI score appears significantly correlated with age differently from NLFS both indices correlated with inflammatory/oxidative stress related parameters, although FLI but no NLFS; correlated with fibrinogen levels (Table 4).

For fibrosis, the scores were differently associated to anthropometric, clinical and laboratory parameters (Table 5). Differently by the other scores, an higher BARD was more frequent in females, whereas FIB-4 did not resulted affected by dyslipidemia or T2D (Table 5). BARD and BAAT were not associated to PLT number (Table 5). High BAAT is associated to high inflammatory-related parameters, and higher FIB-4, FORN and BAAT to increased homocysteine and uric acid levels (Table 5).

\section{DISCUSSION}

Main result of the present study is the evidence of low concordance between steatosis/fibrosis indices in a population with overweight/obesity. As indices consider different parameters in their formula, other than hepatic enzyme that are always included, and showed different relationship with cardiometabolic risk factors, they likely mirror different physiopathological aspect related to liver damage.

FLI score was proposed and evaluated in a Italian population of about 600 subjects, with and without suspected liver disease ${ }^{4}$.

FLI was also used by our group in an observational cross-sectional study enrolling 385 (290 F/94 M, age range 18-69 years) consecutive participants of a nutritional education program; logistic regression between MetS and FLI showed FLI to be a risk factor (odds ratio D 1.051; $95 \%$ confidence interval, 1.039-1.064; $\mathrm{p}<0.001){ }^{2021} \mathrm{NLFS}$ was proposed in 470 no-T2D/T2D subjects $^{22}$, and successively validated in a population of more than 700 consecutive biopsyproven NAFLD patients, where its use was estimated to avoid biopsy in $75 \%$ of patients ${ }^{20}$. Moreover, a meta-analysis including 13 studies shows a pooled AUROC of 0.85 for the diagnosis of advanced fibrosis using the NLFS ${ }^{2}$. We observed a good concordance between, FLI and NLFS (81\%), and both score resulted correlated with inflammatory and anthropometric parameters. Moreover, FLI score correlated with variables included in the NLFS. However, in favour of the FLI index there is the more simplicity of calculation, in fact it requires only four variable (BMI, WC, TG and GGT), easily obtainable, against the evaluation of metabolic syndrome, and the increase in the concentration of insulin, glucose, AST, ALT as well as the decrease in the ratio, necessary for NLFS.

FIB4 comprised age with liver enzymes (ALT, and AST) and PLT count in its calculation. 
First proposed and validated in HIV / HCV co-infected patients $(n=832)$, where the use of FIB4 was estimated to avoid more than $70 \%$ of biopsy ${ }^{16}$. Then, it was applied to a CHC population ( $\mathrm{n}=592)$, where the value $<1.45$ retained a sensitivity of $74 \%$ for excluding severe fibrosis $^{24}$. In addition to its use in HCV, FIB4 may be useful as NAFLD biomarker, with an high negative predictive value, and avoid biopsy in about $60 \%$ of patients ${ }^{5}$. In the present study, between fibrosis indices, FIB4 identify the highest percentage of subjects without fibrosis (85\%), with highest concordance with FORN, especially in the capacity of reciprocal recognition of no-fibrosis patient $(n=673$, Table 3$)$. Both indices contains PLT and aging as determinants in their calculation. In particular, FORN is calculated utilizing a combination of 4 variables identified by comparative analysis of patients with and without significant fibrosis, which included age, GGT, platelet count, and total cholesterol level, this last parameter which in turns inversely correlated with FIB4 (Table 5). Both indices are also related to increased creatinine, glucose, homocysteine levels and significant changes of uric acid concentration.

BARD is the only index, which increase is correlated to a higher percentage of women respect to men. This fact may be related to the inclusion of AST/ALT in the calculation, together with BMI and T2D, which are recognized determinants of fibrosis. In particular, even if both serum AST and ALT values are lower in females than males at all ages, AST/ALT resulted higher in females ${ }^{26}$. Its peculiarity is also evidenced by the low concordance with the other indices (FIB-4, BAAT and FORN), always below $60 \%$.

The panel included in BAAT calculation consists in considering age, BMI, TG, and ALT. In particular, ALT values are often considered a surrogate biomarker of liver disease severity. In patients with advanced fibrosis serum ALT levels was significantly lower than patients with no/mild fibrosis, but the AST levels were similar, resulting in lower AST/ALT ratios in patients with advanced fibrosis, suggesting that ALT might not be the ideal biomarkers to be used to assess fibrosis presence and extent ${ }^{2}$. As previously data evidenced that aging is associated with increase fibrosis, it is notably that FIB-4, FORN, and BAAT did not require to be adjusted for age, which is included in their calculation.

\section{CONCLUSION}

The non-invasive assessment of steatosis/fibrosis tried to overcome some of periprocedural risk of liver biopsy. As these indices are easy to calculate, their use is potentially clinically useful, and may avoid liver biopsy in a part of patients. However, they retain low concordance, and differently correlated with anthropometric, clinical and laboratory variables in a population with overweight/obesity. Thus, these differences between steatosis/fibrosis scores must be considered when expressing a differential liver disease diagnosis or assessing the progression of a known liver disease, since their use will be validated in this clinical context.

\section{What is already known on this subject?}

Other recently published results evidenced the low/moderate concordance between different fibrosis scores applied in diabetes or obese populations, which may reinforce the existence of different pathophysiological background reflected by each score 20235

\section{What this study adds?}

Since non invasive biomarkers of liver fibrosis/steatosis have been widely used in studies involving the general population or primary care, this study showed that the indices evaluated retain low concordance. For this clinicians should be aware of these differences between steatosis/fibrosis scores when expressing a differential liver disease diagnosis or assessing the progression of a known liver disease. 


\section{STRENGHTS AND LIMITATIONS}

Main strenghts of the present study include the large number of subjects enrolled, which allow an adequate analysis according to gender, and the number of laboratory parameters (traditional as well as those more recently proposed) related to the cardiometabolic risk. Conversely, the present study also present limitations that need to be considered. We evaluated non-invasive score to asses liver fibrosis and steatosis without evaluating the real prevalence by using a gold standard technique for steatosis (magnetic resonance spectroscopy or liver biopsy) or fibrosis (liver biopsy). However, it must be considered that our aim was to the accordance of these indices in overweight/obese subjects and evaluate their correlations with other cardiometabolic risk biomarkers.

Another limitation is that many subjects may fall in a gray zone where the diagnosis remains undetermined, that may account, almost in part, for the different concordance between scores. For example, regarding the cut-off $\leq 3.25$ adopted for FIB-4, really this low cut-off is understood to exclude advanced liver fibrosis, but values above this cut-off do not rule in advanced fibrosis and it would not clearly indicate the word "positive" for fibrosis, since there is a large grey area. In this context, recent data, obtained in type 2 diabetes patients, suggest that the use of age-adjusted FIB-4 cut-offs leads to a drop in gray-zone results, rendering selection of patients referring to specialized hepatologists more efficacious, as liver biopsy is not clearly applicable to a large patient portion ${ }^{2}$. Moreover, a possibility to overcome the limitation related to the significant percentage of subjects which remain difficult to categorize, may be a sequential or parallel use of different scores, although this procedure needs to be further verified.

Clearly, we aimed to focus on very common utilized scores, although other indices of steatosis/fibrosis could be evaluated (of particular interest the Hepatic Steatosis Index-HSI and the APRI) in future studies ${ }^{3,34}$

Author Contributions: CV, VL: study conceptualization; DPS, GF TAS, BF, NF, VL data acquisition, and database assessment; $\mathrm{CV}$, data analysis; $\mathrm{MG}$ and CV drafting of the manuscript. GM, CK, DPS, FG, TAS, BF, MM, NF, VL, VC contributed to the manuscript intellectual content and gave approval to the final version.

Conflicts of Interest: The authors declare no conflict of interest.

Funding: This research received no external funding

Institutional Review Board Statement: The study was conducted according to the guidelines of the Declaration of Helsinki, and approved by the Ethics Committee of Milan Policlinico Hospital (Study registration number: 1370).

Data Availability: The datasets generated during and/or analysed during the current study are available from the corresponding author on reasonable request.

\section{REFERENCES}

1. Reilly JJ, El-Hamdouchi A, Diouf A, Monyeki A, Somda SA. Determining the worldwide prevalence of obesity. Lancet. 2018;391(10132). doi:10.1016/S01406736(18)30794-3

2. Eslam M, Newsome PN, Sarin SK, et al. A new definition for metabolic dysfunction- 
associated fatty liver disease: An international expert consensus statement. J Hepatol. 2020;73(1). doi:10.1016/j.jhep.2020.03.039

3. Younossi ZM, Golabi P, de Avila L, et al. The global epidemiology of NAFLD and NASH in patients with type 2 diabetes: A systematic review and meta-analysis. J Hepatol. 2019;71(4). doi:10.1016/j.jhep.2019.06.021

4. $\quad$ Estes C, Anstee QM, Arias-Loste MT, et al. Modeling NAFLD disease burden in China, France, Germany, Italy, Japan, Spain, United Kingdom, and United States for the period 2016-2030. J Hepatol. 2018;69(4). doi:10.1016/j.jhep.2018.05.036

5. Mundi MS, Velapati S, Patel J, Kellogg TA, Dayyeh BKA, Hurt RT. Evolution of NAFLD and Its Management. Nutr Clin Pract. 2020;35(1). doi:10.1002/ncp.10449

6. Schattenberg JM, Straub BK. On the value and limitations of liver histology in assessing non-alcoholic steatohepatitis. J Hepatol. 2020;73(6).

doi:10.1016/j.jhep.2020.07.020

7. ho Lee Y, Cho Y, Lee BW, et al. Nonalcoholic fatty liver disease in diabetes. Part I: Epidemiology and diagnosis. Diabetes Metab J. 2019;43(1). doi:10.4093/ dmj.2019.0011

8. Berzigotti A, Tsochatzis E, Boursier J, et al. EASL Clinical Practice Guidelines on noninvasive tests for evaluation of liver disease severity and prognosis - 2021 update. J Hepatol. 2021;75(3). doi:10.1016/j.jhep.2021.05.025

9. Ciardullo S, Muraca E, Perra S, et al. Screening for non-alcoholic fatty liver disease in type 2 diabetes using non-invasive scores and association with diabetic complications. BMJ Open Diabetes Res Care. 2020;8(1). doi:10.1136/bmjdrc-2019-000904

10. Younossi ZM, Noureddin M, Bernstein D, et al. Role of Noninvasive Tests in Clinical Gastroenterology Practices to Identify Patients With Nonalcoholic Steatohepatitis at High Risk of Adverse Outcomes: Expert Panel Recommendations. Am J Gastroenterol. 2021;116(2). doi:10.14309 / ajg.0000000000001054

11. Chatzianagnostou K, Vigna L, Piazza S Di, et al. Low concordance between HbA1c and OGTT to diagnose prediabetes and diabetes in overweight or obesity. Clin Endocrinol (Oxf). 2019;91(3). doi:10.1111/ cen.14043

12. Puhl R, Suh Y. Health Consequences of Weight Stigma: Implications for Obesity Prevention and Treatment. Curr Obes Rep. 2015;4(2). doi:10.1007/s13679-015-0153-z

13. Puhl RM, Himmelstein MS, Pearl RL. Weight stigma as a psychosocial contributor to obesity. Am Psychol. 2020;75(2). doi:10.1037/ amp0000538

14. Bedogni G, Miglioli L, Masutti F, Tiribelli C, Marchesini G, Bellentani S. Prevalence of and risk factors for nonalcoholic fatty liver disease: The dionysos nutrition and liver study. Hepatology. 2005;42(1). doi:10.1002/ hep.20734

15. Kotronen A, Peltonen M, Hakkarainen A, et al. Prediction of Non-Alcoholic Fatty Liver Disease and Liver Fat Using Metabolic and Genetic Factors. Gastroenterology. 2009;137(3). doi:10.1053/j.gastro.2009.06.005

16. Sterling RK, Lissen E, Clumeck N, et al. Development of a simple noninvasive index to predict significant fibrosis in patients with HIV / HCV coinfection. Hepatology. 2006;43(6). doi:10.1002/ hep.21178

17. Harrison SA, Oliver D, Arnold HL, Gogia S, Neuschwander-Tetri BA. Development and validation of a simple NAFLD clinical scoring system for identifying patients without advanced disease. Gut. 2008;57(10). doi:10.1136/gut.2007.146019

18. Forns X, Ampurdanès S, Llovet JM, et al. Identification of chronic hepatitis C patients without hepatic fibrosis by a simple predictive model. Hepatology. 2002;36(4I). doi:10.1053/jhep.2002.36128

19. Ratziu V, Giral P, Charlotte F, et al. Liver fibrosis in overweight patients. Gastroenterology. 2000;118(6). doi:10.1016/S0016-5085(00)70364-7

20. Xun YH, Fan JG, Zang GQ, et al. Suboptimal performance of simple noninvasive tests for advanced fibrosis in Chinese patients with nonalcoholic fatty liver disease. J Dig Dis. 2012;13(11). doi:10.1111/j.1751-2980.2012.00631.x

21. McPherson S, Stewart SF, Henderson E, Burt AD, Day CP. Simple non-invasive fibrosis scoring systems can reliably exclude advanced fibrosis in patients with nonalcoholic fatty liver disease. Gut. 2010;59(9):1265-1269. doi:10.1136/gut.2010.216077

22. Kotronen A, Peltonen M, Hakkarainen A, et al. Prediction of Non-Alcoholic Fatty Liver Disease and Liver Fat Using Metabolic and Genetic Factors. Gastroenterology. 
2009;137(3). doi:10.1053/j.gastro.2009.06.005

23. Musso G, Gambino R, Cassader M, Pagano G. Meta-analysis: Natural history of nonalcoholic fatty liver disease (NAFLD) and diagnostic accuracy of non-invasive tests for liver disease severity. Ann Med. 2011;43(8). doi:10.3109/07853890.2010.518623

24. Vallet-Pichard A, Mallet V, Nalpas B, et al. FIB-4: An inexpensive and accurate marker of fibrosis in HCV infection. Comparison with liver biopsy and FibroTest. Hepatology. 2007;46(1). doi:10.1002/ hep.21669

25. Shah AG, Lydecker A, Murray K, et al. Comparison of noninvasive markers of fibrosis in patients with nonalcoholic fatty liver disease. Clin Gastroenterol Hepatol. 2009;7(10). doi:10.1016/j.cgh.2009.05.033

26. Mera JR, Dickson B, Feldman M. Influence of gender on the ratio of serum aspartate aminotransferase (AST) to alanine aminotransferase (ALT) in patients with and without hyperbilirubinemia. Dig Dis Sci. 2008;53(3). doi:10.1007/s10620-007-9924-z

27. McPherson S, Stewart SF, Henderson E, Burt AD, Day CP. Simple non-invasive fibrosis scoring systems can reliably exclude advanced fibrosis in patients with nonalcoholic fatty liver disease. Gut. 2010;59(9). doi:10.1136/gut.2010.216077

28. Targher G, Lonardo A, Byrne CD. Nonalcoholic fatty liver disease and chronic vascular complications of diabetes mellitus. Nat Rev Endocrinol. 2018;14(2). doi:10.1038/nrendo.2017.173

29. Singh A, Le P, Peerzada MM, Lopez R, Alkhouri N. The Utility of Noninvasive Scores in Assessing the Prevalence of Nonalcoholic Fatty Liver Disease and Advanced Fibrosis in Type 2 Diabetic Patients. In: Journal of Clinical Gastroenterology. Vol 52. ; 2018. doi:10.1097/MCG.0000000000000905

30. Ciardullo S, Ronchetti C, Muraca E, et al. Impact of using different biomarkers of liver fibrosis on hepatologic referral of individuals with severe obesity and NAFLD. J Endocrinol Invest. 2020;43(7). doi:10.1007/s40618-020-01188-7

31. Ciardullo S, Sala I, Perseghin G. Screening strategies for nonalcoholic fatty liver disease in type 2 diabetes: Insights from NHANES 2005-2016. Diabetes Res Clin Pract. 2020;167. doi:10.1016/j.diabres.2020.108358

32. Ciardullo S, Ronchetti C, Muraca E, et al. Impact of using different biomarkers of liver fibrosis on hepatologic referral of individuals with severe obesity and NAFLD. J

Endocrinol Invest. 2020;43(7). doi:10.1007/ s40618-020-01188-7

33. Lee JH, Kim D, Kim HJ, et al. Hepatic steatosis index: A simple screening tool reflecting nonalcoholic fatty liver disease. Dig Liver Dis. 2010;42(7). doi:10.1016/j.dld.2009.08.002

34. Lin ZH, Xin YN, Dong QJ, et al. Performance of the aspartate aminotransferase-toplatelet ratio index for the staging of hepatitis C-related fibrosis: An updated metaanalysis. Hepatology. 2011;53(3). doi:10.1002/ hep.24105 


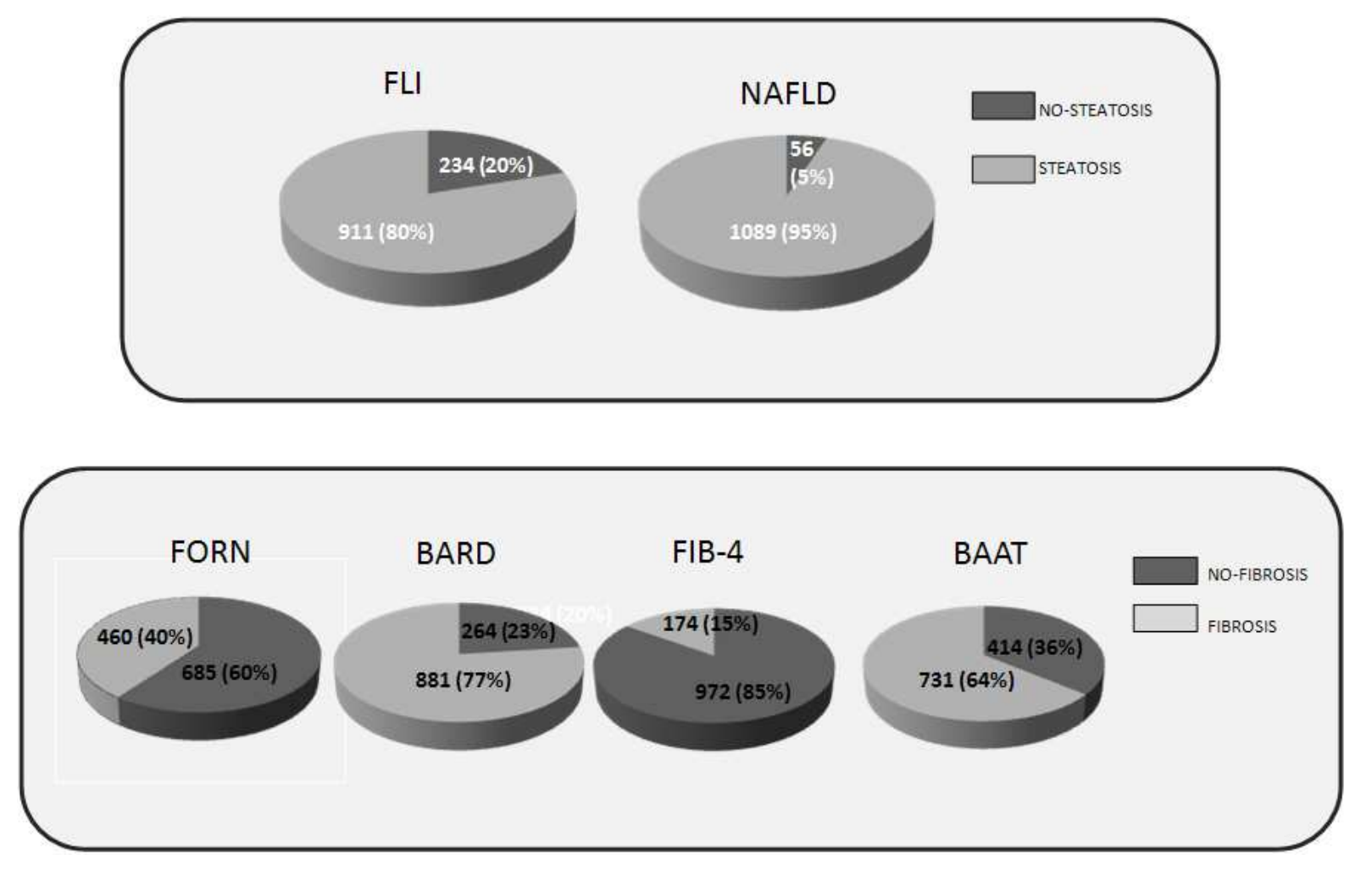

FIGURE 1. Number and percentage of subjects with fibrosis or steatosis according to the non-invasive score criteria. 


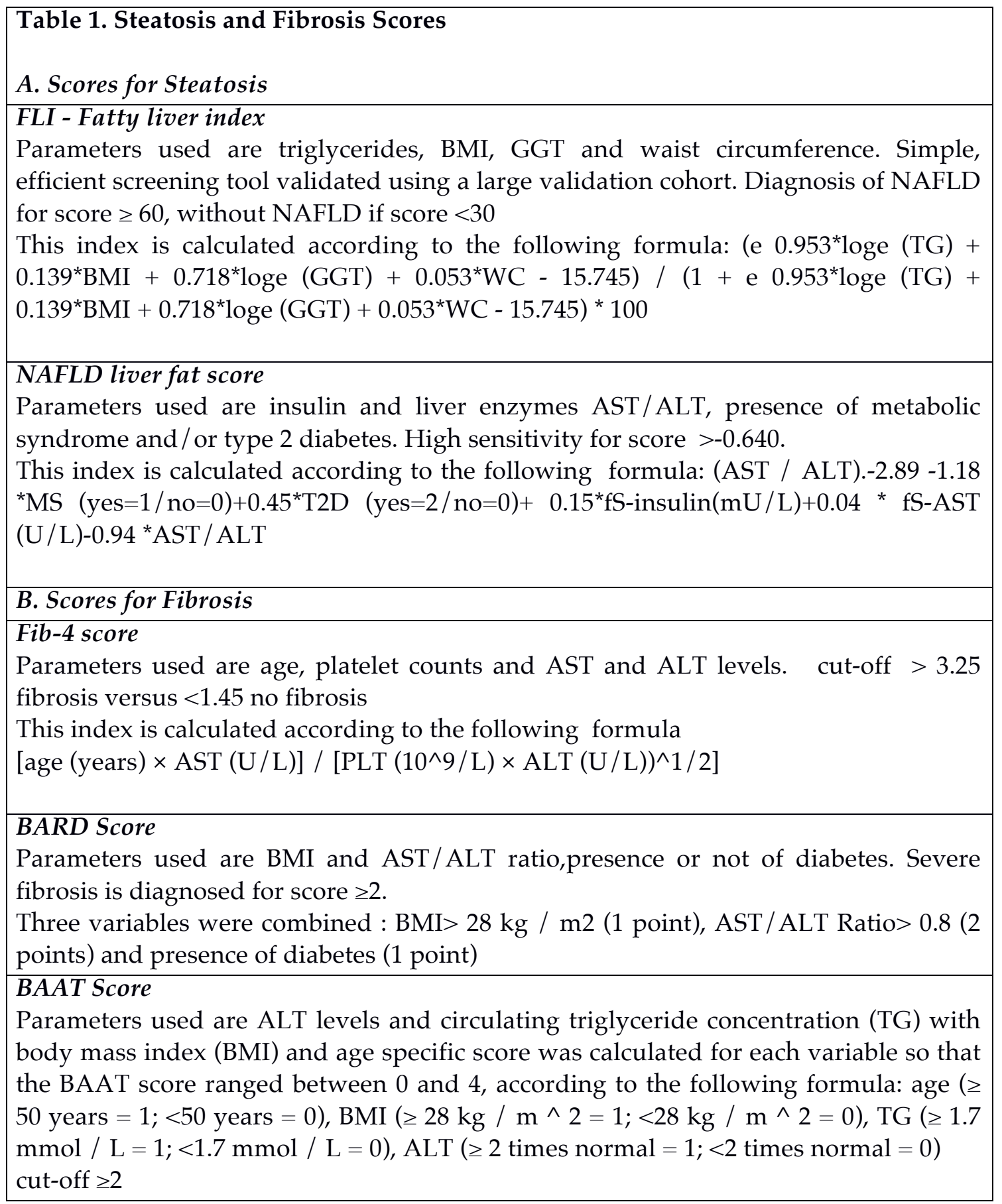

Table 2 Clinical, anthropometric characteristics of study subjects

\begin{tabular}{l|ll}
\hline & $\mathbf{N}$ & $\mathbf{1 1 4 5}$ \\
\hline Clinical Characteristics & Females & $856(75 \%)$ \\
\hline & Age (years) & $54 \pm 14$ \\
\hline & Waist circumference & $100 \pm 14$ \\
\hline & Body Mass Index $(\mathrm{Kg} / \mathrm{m} 2)$ & $34 \pm 4$ \\
\hline & Obesity & $740(74 \%)$ \\
\hline
\end{tabular}




\begin{tabular}{|c|c|c|}
\hline & Diastolic blood pressure (mmHg) & $78 \pm 8$ \\
\hline & Systolic blood pressure (mmHg) & $126 \pm 14$ \\
\hline & Hypertension & $353(31 \%)$ \\
\hline & Dyslipidemia & $643(56 \%)$ \\
\hline & $\mathrm{T} 2 \mathrm{D}$ & $174(15 \%)$ \\
\hline \multirow[t]{2}{*}{ Non-invasive steatosis scores } & FLI & $60 \pm 29$ \\
\hline & NAFDL LIVER FAT SCORE & $2.7 \pm 3.3$ \\
\hline \multirow[t]{4}{*}{ Non invasive fibrosis scores } & FIB4 & $1.1 \pm 0.6$ \\
\hline & $\operatorname{BARD}(\geq 2)$ & $881(77 \%)$ \\
\hline & FORN & $3.8 \pm 1.6$ \\
\hline & BAAT $(\geq 2)$ & $731(64 \%)$ \\
\hline \multirow[t]{21}{*}{ Laboratory parameters } & Creatinine (mg/dL) & $0.76(0.67-0.88)$ \\
\hline & Glucose (mg/dL) & $95(88-104)$ \\
\hline & 120 min-Glucose OGTT (mg/dL) & $101(98-115)$ \\
\hline & Insulin (mUI/mL) & $11.7(8-17.4)$ \\
\hline & 120 min-Insulin OGTT (mUI/mL) & $42.2(26.4-66.8)$ \\
\hline & Glycated haemoglobin $(\%) ;(\mathrm{mmol} / \mathrm{mol})$ & $5.6 \% ; 38(35-42)$ \\
\hline & Total cholesterol (mg/dL) & $203 \pm 39$ \\
\hline & High density lipoproteins (mg/dL) & $59 \pm 15$ \\
\hline & Tryglicerides (mg/dL) & $102(75-134)$ \\
\hline & Low density lipoproteins (mg/dL) & $129 \pm 34$ \\
\hline & Gamma-glutamyl transferase (UI/L) & $18(13-26)$ \\
\hline & Aspartate aminotransferase (UI/L) & $19(16-23)$ \\
\hline & Alanine aminotransferase (UI/L) & $20(15-28)$ \\
\hline & Platelets (109/L) & $245 \pm 59$ \\
\hline & Neutrophils (109/L) & $3.8(3-4.6)$ \\
\hline & Monocytes (109/L) & $2.1 \pm 0.6$ \\
\hline & Lymphocytes (109/L) & $4.9 \pm 1.6$ \\
\hline & Fibrinogen (mg/dL) & $325(283-367)$ \\
\hline & $\mathrm{C}$ reactive protein $(\mathrm{mg} / \mathrm{dL})$ & $0.26(0.13-0.53)$ \\
\hline & Homocysteine (mmol/L) & $10.9(9.1-13.9-3)$ \\
\hline & Uric acid (mg/dL) & $5.1 \pm 1.3$ \\
\hline
\end{tabular}

Table 3 Concordance between noninvasive steatosis and fibrosis scores in the overall population

\begin{tabular}{|l|l|l|l|l|}
\hline Non-invasive steatosis scores & \multicolumn{3}{|l|}{ FLI } & \\
\hline & & $\leq 30$ & $>30$ \\
\hline \multirow{2}{*}{ NAFLD LIVER FAT SCORE } & $\leq-0.64$ & 39 & 17 \\
\cline { 2 - 5 } & $>-0.64$ & 195 & 894 \\
\hline
\end{tabular}




\begin{tabular}{|c|c|c|c|c|c|c|c|}
\hline \multicolumn{8}{|c|}{ Non-invasive fibrosis scores } \\
\hline & & \multicolumn{2}{|l|}{ FIB4 } & \multicolumn{2}{|c|}{ BARD } & \multicolumn{2}{|c|}{ FORN } \\
\hline & & $\leq 3.25$ & $>3.25$ & $<2$ & $\geq 2$ & $\leq 4.2$ & $>4.2$ \\
\hline \multirow{2}{*}{ BARD } & $<2$ & 250 & 14 & & & & \\
\hline & $\geq 2$ & 772 & 159 & & & & \\
\hline \multirow{2}{*}{ FORN } & $\leq 4.2$ & 673 & 12 & 165 & 520 & & \\
\hline & $>4.2$ & 298 & 162 & 99 & 361 & & \\
\hline \multirow{2}{*}{ BAAT } & $<2$ & 386 & 28 & 99 & 315 & 336 & 77 \\
\hline & $\geq 2$ & 586 & 145 & 165 & 566 & 349 & 382 \\
\hline
\end{tabular}

Table 4. Association between steatosis scores and clinical and biochemical characteristics in overweight and obese subjects (subject with overweight and obesity)

\begin{tabular}{|c|c|c|c|c|}
\hline & \multicolumn{2}{|c|}{ FATTY LIVER INDEX } & \multicolumn{2}{|c|}{ NAFLD LIVER FAT } \\
\hline & $\leq 30$ & $>30$ & $\leq-0.64$ & $>-0.64$ \\
\hline MALE GENDER ( \%) & $8(3)$ & $281(30)^{\star * *}$ & $4(7)$ & $285(26)^{* *}$ \\
\hline AGE (YEARS) & $51 \pm 15$ & $55 \pm 14^{\star \star *}$ & $52 \pm 14$ & $54 \pm 14$ \\
\hline $\begin{array}{l}\text { WAIST CIRCUMFERENCE } \\
(\mathrm{cm})\end{array}$ & - & - & - & - \\
\hline $\begin{array}{l}\text { BODY MASS INDEX } \\
\text { (KG/M2) }\end{array}$ & - & - & - & - \\
\hline $\begin{array}{l}\text { DIASTOLIC BLOOD } \\
\text { PRESSURE (MMHG) }\end{array}$ & $75 \pm 9$ & $79 \pm 8^{* * *}$ & - & - \\
\hline $\begin{array}{l}\text { SYSTOLIC BLOOD } \\
\text { PRESSURE (MMHG) }\end{array}$ & $121 \pm 15$ & $127 \pm 14^{\star * \star}$ & - & - \\
\hline CREATININe (MG/DL) & $0.7 \pm 0.1$ & $0.8 \pm 0.2^{* * *}$ & $0.8 \pm 0.1$ & $0.8 \pm 0.2$ \\
\hline GLUCOSE (MG/DL) & 89 (83-95) & $97(89-106)^{* \star *}$ & - & - \\
\hline $\begin{array}{l}120 \text { MIN-GLUCOSE OGTT } \\
\text { (MG/DL) }\end{array}$ & $94(86-104)$ & $103(93-118)^{* * *}$ & - & - \\
\hline INSULIN (MUI/ML) & $7.3(5.8-10)$ & $13.2(9.1-18.7)^{* * *}$ & - & - \\
\hline $\begin{array}{l}120 \text { MIN-INSULIN OGTT } \\
\text { (MUI/ML) }\end{array}$ & $26(17.5-40.2)$ & $47.6(30.8-74.9)^{\star \star \star}$ & - & - \\
\hline $\begin{array}{l}\text { GLYCATED } \\
\text { HAEMOGLOBIN } \\
(\%) ;(M M O L / M O L)\end{array}$ & $5.5 ; 37(34-39)$ & $5.7 ; 39(36-43)^{\star \star \star}$ & - & - \\
\hline $\begin{array}{l}\text { TOTAL CHOLESTEROL } \\
\text { (MG/DL) }\end{array}$ & $200 \pm 37$ & $204 \pm 40$ & $208 \pm 43$ & $203 \pm 39$ \\
\hline $\begin{array}{l}\text { HIGH DENSITY } \\
\text { LIPOPROTEINS (MG/DL) }\end{array}$ & $68 \pm 15$ & $57 \pm 15^{\star \star \star}$ & - & - \\
\hline $\begin{array}{l}\text { TRYGLICERIDES } \\
\text { (MG/DL) }\end{array}$ & - & - & - & - \\
\hline $\begin{array}{l}\text { LOW DENSITY } \\
\text { LIPOPROTEINS (MG/DL) }\end{array}$ & - & - & - & - \\
\hline PLATELETS (109/L) & $245 \pm 55$ & $245 \pm 60$ & $245 \pm 59$ & $245 \pm 60$ \\
\hline
\end{tabular}




\begin{tabular}{|c|c|c|c|c|}
\hline NEUTROPHILS (109/L) & $3.3(2.7-4)$ & $3.9(3.1-4.7)^{\star * *}$ & $3.2(2.6-3.9)$ & $3.8(3.1-4.7)^{* * *}$ \\
\hline MONOCYTES (109/L) & $1.9(1.5-2.2)$ & $2(1.7-2.5)^{* * *}$ & $1.8(1.5-2.1)$ & $2(1.7-2.4)^{\star *}$ \\
\hline LYMPHOCYTES (109/L) & $4.4 \pm 1$ & $5 \pm 2^{* * *}$ & $4.4 \pm 1.3$ & $5 \pm 1.7^{*}$ \\
\hline FIBRINOGEN (MG/DL) & $316(274-355)$ & $328(285-368)^{\star *}$ & $332(286-362)$ & $325(283-367)$ \\
\hline $\begin{array}{l}\text { C REACTIVE PROTEIN } \\
\text { (MG/DL) }\end{array}$ & $0.2(0.1-0.3)$ & $0.3(0.1-0.6)^{\star * *}$ & $0.2(0.1-0.4)$ & $0.3(0.1-0.5)^{\star *}$ \\
\hline $\begin{array}{l}\text { HOMOCYSTEINE } \\
(\mathrm{mMOL} / \mathrm{L})\end{array}$ & $9.8(8.1-11.5)$ & $11.3(9.3-13.9)^{* * *}$ & $10.2(8.3-12.2)$ & $10.9(9.1-13.4)^{*}$ \\
\hline URIC ACID (MG/DL) & $4.4 \pm 1$ & $5.3 \pm 1.4^{* \star \star}$ & $4.8 \pm 1$ & $5.2 \pm 1.4^{*}$ \\
\hline
\end{tabular}

Table 5. Association between fibrosis scores and clinical and biochemical characteristics in overweight and obese subjects (subject with overweight and obesity)

\begin{tabular}{|c|c|c|c|c|c|c|c|c|}
\hline & FIB4 & & BARD & & FORN & & BAAT & \\
\hline & $\leq 3.25$ & $>3.25$ & $<2$ & $\geq 2$ & $\leq 4.2$ & $>4.2$ & $<2$ & $\geq 2$ \\
\hline MALE GENDER (\%) & $206(21)$ & $83(29)^{* * *}$ & $\begin{array}{l}103 \\
(39)\end{array}$ & $\begin{array}{l}186 \\
(21)^{\star * *}\end{array}$ & $\begin{array}{l}116 \\
(16)\end{array}$ & $\begin{array}{l}173 \\
(38)^{* * *}\end{array}$ & $89(21)$ & $200(27)^{\star}$ \\
\hline AGE (YEARS) & - & - & $50 \pm 13$ & $56 \pm 14^{* * *}$ & - & - & - & - \\
\hline WAIST CIRCUMFERENCE & $100 \pm 13$ & $103 \pm 15^{* *}$ & - & - & $98 \pm 13$ & $104 \pm 14^{* * *}$ & $94 \pm 13$ & $104 \pm 13^{* * *}$ \\
\hline BODY MASS INDEX (KG/M2) & $33 \pm 5$ & $33 \pm 6$ & - & - & $33 \pm 5$ & $34 \pm 5$ & - & - \\
\hline $\begin{array}{l}\text { DIASTOLIC BLOOD PRESSURE } \\
\text { (MMHG) }\end{array}$ & $78 \pm 8$ & $78 \pm 8$ & $80 \pm 8$ & $77 \pm 8^{\star * *}$ & $77 \pm 8$ & $79 \pm 8^{* * *}$ & $76 \pm 8$ & $79 \pm 8^{* * *}$ \\
\hline $\begin{array}{l}\text { SYSTOLIC BLOOD PRESSURE } \\
\text { (MMHG) }\end{array}$ & $125 \pm 14$ & $131 \pm 15^{* * *}$ & $125 \pm 13$ & $127 \pm 15$ & $124 \pm 14$ & $130 \pm 14^{* * *}$ & $121 \pm 13$ & $129 \pm 14^{* * *}$ \\
\hline CREATININ (MG/DL) & $0.87 \pm 0.2$ & $0.9 \pm 0.2^{* * *}$ & $0.8 \pm 0.2$ & $0.8 \pm 0.2$ & $0.7 \pm 0.2$ & $0.9 \pm 0.2^{* * *}$ & $0.7 \pm 0.2$ & $0.8 \pm 0.2^{* * *}$ \\
\hline GLUCOSE (MG/DL) & $\begin{array}{l}94(87- \\
103)\end{array}$ & $\begin{array}{l}99(91- \\
107)^{* * *}\end{array}$ & - & - & $\begin{array}{l}92(86- \\
99)\end{array}$ & $\begin{array}{l}100(92- \\
110)^{* * *}\end{array}$ & $\begin{array}{l}90(84- \\
97)\end{array}$ & $\begin{array}{l}97(91- \\
108)^{* * *}\end{array}$ \\
\hline $\begin{array}{l}120 \text { MIN-GLUCOSE OGTT } \\
\text { (MG/DL) }\end{array}$ & $\begin{array}{l}100(90- \\
114)\end{array}$ & $\begin{array}{l}104(95- \\
117)^{*}\end{array}$ & - & - & $\begin{array}{l}99(89- \\
110)\end{array}$ & $\begin{array}{l}106(95- \\
125)^{* * *}\end{array}$ & $\begin{array}{l}95(86- \\
105)\end{array}$ & $\begin{array}{l}105(95- \\
121)^{* * *}\end{array}$ \\
\hline INSULIN (MUI/ML) & $\begin{array}{l}11.6(8- \\
17.3)\end{array}$ & $\begin{array}{l}11.6(7.6- \\
17)\end{array}$ & - & - & $\begin{array}{l}11 \\
(7.5- \\
16)\end{array}$ & $\begin{array}{l}12.9(8.8- \\
18.9)^{* * *}\end{array}$ & $\begin{array}{l}10.2 \\
(7.2- \\
14.9)\end{array}$ & $\begin{array}{l}12.7(8.4- \\
18.7)^{\star * *}\end{array}$ \\
\hline
\end{tabular}




\begin{tabular}{|c|c|c|c|c|c|c|c|c|}
\hline $\begin{array}{l}120 \text { MIN-INSULIN OGTT } \\
\text { (MUI/ML) }\end{array}$ & $\begin{array}{l}42(26- \\
66.6)\end{array}$ & $\begin{array}{l}41.9 \\
(27.1- \\
67.2)\end{array}$ & - & - & $\begin{array}{l}39.2 \\
(24.7- \\
61.3)\end{array}$ & $\begin{array}{l}46.5(30- \\
74.8)^{* * *}\end{array}$ & $\begin{array}{l}34.2 \\
(22.2- \\
56.3)\end{array}$ & $\begin{array}{l}46.5(30- \\
72.9)^{* * *}\end{array}$ \\
\hline $\begin{array}{l}\text { GLYCATED } \\
\text { HAEMOGLOGIN(\%);(MMOL/MOL) }\end{array}$ & $\begin{array}{l}5.6 ; 38 \\
(35-42)\end{array}$ & $\begin{array}{l}5.7 ; 39 \\
(36-42)^{*}\end{array}$ & - & - & $\begin{array}{l}5.6 ; 38 \\
(34-41)\end{array}$ & $\begin{array}{l}5.8 ; 40 \\
(37-44)^{* * *}\end{array}$ & $\begin{array}{l}5.6 ; 38 \\
(33-39)\end{array}$ & $\begin{array}{l}5.8 ; 40 \\
(37-44)^{* * *}\end{array}$ \\
\hline TOTAL CHOLESTEROL (MG/DL) & $205 \pm 39$ & $200 \pm 41^{*}$ & $206 \pm 37$ & $203 \pm 40$ & - & - & $195 \pm 37$ & $208 \pm 40^{* * *}$ \\
\hline $\begin{array}{l}\text { HIGH DENSITY LIPOPROTEINS } \\
\text { (MG/DL) }\end{array}$ & $59 \pm 15$ & $59 \pm 16$ & $55 \pm 14$ & $60 \pm 16^{* * *}$ & $60 \pm 15$ & $58 \pm 16^{*}$ & $61 \pm 15$ & $58 \pm 16^{* *}$ \\
\hline TRYGLICERIDES (MG/DL) & $\begin{array}{l}103(75- \\
135)\end{array}$ & $\begin{array}{l}99(73- \\
133)\end{array}$ & $\begin{array}{l}114 \\
(80- \\
152)\end{array}$ & $\begin{array}{l}99(73- \\
129)^{* * *}\end{array}$ & $\begin{array}{l}102 \\
(74- \\
134)\end{array}$ & $\begin{array}{l}102(76- \\
137)\end{array}$ & - & - \\
\hline $\begin{array}{l}\text { LOW DENSITY LIPOPROTEINS } \\
\text { (MG/DL) }\end{array}$ & $\begin{array}{l}128 \\
(106- \\
151)\end{array}$ & $\begin{array}{l}122(103- \\
143)^{*}\end{array}$ & $\begin{array}{l}131 \\
(110- \\
152)\end{array}$ & $\begin{array}{l}126(104- \\
148)^{*}\end{array}$ & - & - & - & - \\
\hline PLATELETS (109/L) & - & - & $241 \pm 52$ & $246 \pm 60$ & - & - & $250 \pm 60$ & $241 \pm 58^{*}$ \\
\hline NEUTROPHILS (109/L) & $\begin{array}{l}3.8(3.1- \\
4.7)\end{array}$ & $\begin{array}{l}3.4(2.9- \\
4.2)^{* * *}\end{array}$ & $\begin{array}{l}4(3.1- \\
4.8)\end{array}$ & $\begin{array}{l}3.7(3- \\
4.6)^{*}\end{array}$ & $\begin{array}{l}3.9 \\
(3.2- \\
4.7)\end{array}$ & $\begin{array}{l}3.6(2.8- \\
4.5)^{* * *}\end{array}$ & $\begin{array}{l}3.7(3- \\
4.5)\end{array}$ & $\begin{array}{l}3.8(3.1- \\
4.7)^{*}\end{array}$ \\
\hline MONOCYTES (109/L) & $\begin{array}{l}2(1.7- \\
2.5)\end{array}$ & $\begin{array}{l}1.9(1.4- \\
2.2)^{* * *}\end{array}$ & $\begin{array}{l}2.1 \\
(1.7- \\
2.5)\end{array}$ & $\begin{array}{l}2(1.7- \\
2.4)\end{array}$ & $\begin{array}{l}2.1 \\
(1.7- \\
2.5)\end{array}$ & $\begin{array}{l}1.9(1.6- \\
2.4)^{* * *}\end{array}$ & $\begin{array}{l}2(1.6- \\
2.4)\end{array}$ & $\begin{array}{l}2(1.7- \\
2.4)\end{array}$ \\
\hline LYMPHOCYTES (109/L) & $4.9 \pm 1.7$ & $4.8 \pm 1.5$ & $5 \pm 1.7$ & $4.8 \pm 1.6$ & $4.9 \pm 1.6$ & $4.9 \pm 1.7$ & $4.6 \pm 1.4$ & $5 \pm 1.7^{* * *}$ \\
\hline FIBRINOGEN (MG/DL) & $\begin{array}{l}328 \\
(284- \\
368)\end{array}$ & $\begin{array}{l}309(272- \\
350)^{* *}\end{array}$ & $\begin{array}{l}323 \\
(282- \\
363)\end{array}$ & $\begin{array}{l}328(283- \\
367)\end{array}$ & $\begin{array}{l}332 \\
(289- \\
368)\end{array}$ & $\begin{array}{l}314(276- \\
363)^{* *}\end{array}$ & $\begin{array}{l}315 \\
(273- \\
355)\end{array}$ & $\begin{array}{l}332(289- \\
373)^{* * *}\end{array}$ \\
\hline C REACTIVE PROTEIN (MG/DL) & $\begin{array}{l}0.3(0.1- \\
0.5)\end{array}$ & $\begin{array}{l}0.2(0.1- \\
0.4)^{* * *}\end{array}$ & $\begin{array}{l}0.3 \\
(0.1- \\
0.6)\end{array}$ & $\begin{array}{l}0.3(0.1- \\
0.5)\end{array}$ & $\begin{array}{l}0.3 \\
(0.1- \\
0.6)\end{array}$ & $\begin{array}{l}0.2(0.1- \\
0.5)^{*}\end{array}$ & $\begin{array}{l}0.2 \\
(0.1- \\
0.46)\end{array}$ & $\begin{array}{l}0.3(0.15- \\
0.6)^{* * *}\end{array}$ \\
\hline HOMOCYSTEINE (MMOL/L) & $\begin{array}{l}10.7 \\
(8.9- \\
13.1)\end{array}$ & $\begin{array}{l}12.2 \\
(10.4- \\
14.5)^{\star * \star}\end{array}$ & $\begin{array}{l}10.5 \\
(8.9- \\
13)\end{array}$ & $\begin{array}{l}11(9.2- \\
13.4)\end{array}$ & $\begin{array}{l}10.4 \\
(8.6- \\
12.5)\end{array}$ & $\begin{array}{l}11.7(9.9- \\
14.2)^{* * *}\end{array}$ & $\begin{array}{l}10.3 \\
(8.5- \\
12)\end{array}$ & $\begin{array}{l}11.4(9.5- \\
13.9)^{* * *}\end{array}$ \\
\hline URIC ACID (MG/DL) & $5.1 \pm 1.3$ & $5.5 \pm 1.4^{\star * *}$ & $5.4 \pm 1.4$ & $5.1 \pm 1.3^{\star * *}$ & $4.9 \pm 1.2$ & $5.5 \pm 1.4^{* \star *}$ & $4.8 \pm 1.2$ & $5.4 \pm 1.4^{* * *}$ \\
\hline
\end{tabular}

